\title{
Simple and Fast Methods Based on Solid-Phase Extraction Coupled to Liquid Chromatography with UV Detection for the Monitoring of Caffeine in Natural, and Wastewater as Marker of Anthropogenic Impact
}

\author{
Sònia Moret, Manuela Hidalgo, and Juan M. Sanchez \\ Department of Chemistry, University of Girona, Montilivi Campus, s/n, 17071 Girona, Spain \\ Correspondence should be addressed to Juan M. Sanchez, juanma.sanchez@udg.edu
}

Received 12 December 2011; Accepted 2 January 2012

Academic Editors: I. Brondz, G. K. Jayaprakasha, H. Naranmandura, and F. Pellati

Copyright (C) 2012 Sònia Moret et al. This is an open access article distributed under the Creative Commons Attribution License, which permits unrestricted use, distribution, and reproduction in any medium, provided the original work is properly cited.

\begin{abstract}
Two concentration methods for fast and routine determination of caffeine (using HPLC-UV detection) in surface, and wastewater are evaluated. Both methods are based on solid-phase extraction (SPE) concentration with octadecyl silica sorbents. A common "offline" SPE procedure shows that quantitative recovery of caffeine is obtained with $2 \mathrm{~mL}$ of an elution mixture solvent methanolwater containing at least $60 \%$ methanol. The method detection limit is $0.1 \mu \mathrm{g} \mathrm{\textrm {L } ^ { - 1 }}$ when percolating $1 \mathrm{~L}$ samples through the cartridge. The development of an "online" SPE method based on a mini-SPE column, containing $100 \mathrm{mg}$ of the same sorbent, directly connected to the HPLC system allows the method detection limit to be decreased to $10 \mathrm{ng} \mathrm{L}^{-1}$ with a sample volume of $100 \mathrm{~mL}$. The "offline" SPE method is applied to the analysis of caffeine in wastewater samples, whereas the "on-line" method is used for analysis in natural waters from streams receiving significant water intakes from local wastewater treatment plants.
\end{abstract}

\section{Introduction}

Caffeine is the world most widely-consumed psychoactive stimulant. It is possible to find this alkaloid in foods, beverages and drug preparations, and the daily average load has been estimated at between 16 and $70 \mathrm{mg}_{\text {person }}{ }^{-1}$ day $^{-1}$ $[1,2]$.

The amounts of caffeine reaching wastewaters in urban areas are considerable since (i) large amounts of caffeine go directly down the drains from unconsumed drinks (e.g., coffee, tea, and soft drinks) and the rinsing of pots and cups [3], and (ii) $0.5-3 \%$ of human caffeine intake is excreted in a nonmetabolized form by urine $[4,5]$. Caffeine has been found to reach values of around $100 \mu \mathrm{g} \cdot \mathrm{L}^{-1}[2,6]$ in the influents of wastewater treatment plants (WWTPs) and is one of the compounds that most contribute to the total mass loads of pharmaceuticals in these plants [7].

On the Costa Brava (Girona, Spain), a large percentage of the wastewater treated by WWTPs is reused for the irrigation of fields, golf courses, and public gardens as well as to feed natural streams for the recovery of their natural flow and ecological quality. Given these uses, it is extremely important that microcontaminants be removed in the WWTPs.

In selecting chemical markers of anthropogenic impact, it is necessary to use ones that are able to distinguish wastewater inputs from both treated and non-treated sources $[2,8]$. Such a compound would have to be largely eliminated in WWTPs. Caffeine, therefore, may be regarded as a suitable marker given that $>99 \%$ can be degraded in WWTPs $[2,6$, $7,9,10]$. Henjum et al. [11] used caffeine as an indicator for domestic wastewater discharges in streams located in places where no direct wastewater discharges were expected and so where wastewater inputs could be attributed to combined sewer overflows or septic drainage fields.

The objectives of this study were, firstly, to develop a simple and fast analytical methodology to determine caffeine in environmental and waste waters, and, secondly, to evaluate the efficiency of three selected WWTPs of the Costa Brava area in removing caffeine at different treatment stages, and, finally, to monitor caffeine as a marker of 
untreated wastewater in three natural streams receiving significant water intakes from local WWTPs.

\section{Experimental}

2.1. Chemicals and Reagents. Caffeine (1,3,7-trimethylxanthine, 99\%) was obtained from Aldrich (Steinheim, Germany). The solvents used (acetonitrile and methanol) were HPLC grade (Carlo Erba, Milan, Italy). Ultra-pure water was obtained from a MilliQ system (Millipore Iberica S.A., Barcelona, Spain).

Stock solutions of caffeine (ca. $500 \mathrm{mg} \cdot \mathrm{L}^{-1}$ ) were prepared in methanol. These solutions were stored for up to one week in amber vials at $4^{\circ} \mathrm{C}$. Working solutions were prepared daily by diluting and mixing the stock with MilliQ water.

Solid-phase extraction AccuBond II ODS cartridges (500 mg, $3 \mathrm{~mL}$ volume, $55 \mu \mathrm{m}$ particle diameter, and surface area of $\left.546 \mathrm{~m}^{2} \cdot \mathrm{g}^{-1}\right)$ were used in the clean-up and concentration steps (Agilent Technologies UK Ltd., West Lothian, UK).

2.2. Study Area. The area under study is located on the Costa Brava, the coastal area of the Girona province, north-eastern Spain. This is a popular tourist area on the Mediterranean and as a result there are significant oscillations in the population between seasons.

Three WWTPs (Empuriabrava, Pals and Palamós) were selected for the evaluation of the efficiency of caffeine removal in the water treatment of urban wastewaters. The treatment process includes grit removal and screening, primary settling and activated sludge biological processing in all the plants. This is followed by UV/chlorination disinfection in Palamós and Pals, whereas Empuriabrava WWTP has a tertiary stage of lagoons and three constructed wetlands that feed the "Aiguamolls de l'Empordà" natural park. In all the WWTPs the study was performed during July 2005, a period when these WWTPs were operating at their greatest capacity due to the significant seasonal increase in the local population, and in October 2005, when the level of tourism was considerably lower.

Surface waters from three streams (Riera de Tossa, Riera d'Aubí and Riu Ridaura) were evaluated. Three local WWTPs that feed these streams were also evaluated to determine whether the source of caffeine detected in the streams was associated to effluent discharges from the plants.

2.3. Sampling and Analysis. Two liters of sample was collected at each sampling point. It was filtered through glass microfiber filters (Whatman, Maidstone, UK) to eliminate suspended particles, and stored in amber glass bottles at $4^{\circ} \mathrm{C}$ until analysis (maximum 48 hours).

Concentration and clean-up steps were performed by solid phase extraction (SPE). For the "off-line" concentration procedure, SPE cartridges were conditioned with $2 \mathrm{~mL}$ methanol and $2 \mathrm{~mL}$ milli. $\mathrm{Q}$ water. Samples were loaded in the cartridges at $25 \mathrm{~mL} \mathrm{~min}{ }^{-1}$ and sorbents were then dried for $30 \mathrm{~s}$ with a vacuum pump. Desorption of caffeine was achieved with $2 \mathrm{~mL}$ methanol: water $(60: 40) .20 \mu \mathrm{L}$ of the final eluate was analyzed by HPLC-UV.

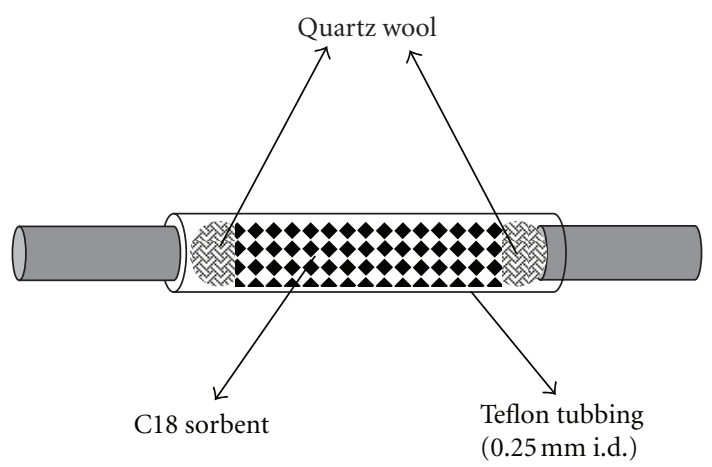

Figure 1: The mini-SPE column design.

For the "on-line" concentration procedure, a mini-SPE column (Figure 1$)$ made of Teflon tubing $(0.25 \mathrm{~mm}$ i.d.) was prepared. A quartz wool plug was inserted in one end and $100 \mathrm{mg}$ of AccuBond II ODS particles were introduced. This was then plugged by a second piece of quartz wool and the excess tubing was cut off. The mini-SPE column was conditioned with $1 \mathrm{~mL}$ methanol and $1 \mathrm{~mL}$ milli. $\mathrm{Q}$ water before a sample was passed through the column. The column was then dried by passing dry air through the column for 60 seconds. Caffeine was desorbed with $0.3 \mathrm{~mL}$ methanol and the valve was turned to direct the elution volume to the injection valve of the HPLC instrument for analysis (Figure 2).

HPLC analyses were performed on a Shimadzu chromatograph (Kyoto, Japan) equipped with two pumps (LC9A) and a UV-Visible spectrophotometric detector (SPD$6 \mathrm{AU})$. Separation was carried out on a $20 \times 0.46 \mathrm{~cm}$ i.d. column packed with a $5 \mu \mathrm{m}$ Kromasil $100 \mathrm{C} 18$ silica phase (Teknokroma, Barcelona, Spain) at $25 \pm 1^{\circ} \mathrm{C}$. An ODS precolumn was used (TR-C-160-1, Teknokroma). The mobile phase consisted of an acetonitrile-water solution $(20: 80$, isocratic) at a flow rate of $1 \mathrm{~mL} \mathrm{~min}{ }^{-1}$. Samples were injected by means of a Rheodyne 7725i injector (Rohnert Park, CA, USA) with a $20 \mu \mathrm{L}$ sample loop. UV detection at $272 \mathrm{~nm}$ was used.

\section{Results and Discussion}

3.1. HPLC Analysis of Surface and Waste Water Samples. Determination of caffeine in water samples is usually performed by GC-MS $[2,9,12]$ or LC-MS [13-16]. These methodologies allow detection limits in the range of $\mathrm{ng} \mathrm{L}^{-1}$ to be reached but require the use of complex and expensive instrumentation. Simpler and cheaper instrumentation is preferred in non-research laboratories where routine analyses are performed. HPLC-UV can also be applied for the analysis of caffeine in water samples. The evaluation of the HPLC-UV method described in the experimental section yielded a limit of detection (LOD) of $1 \mu \mathrm{g} \mathrm{L}^{-1}$ (3s blank criteria, where $s_{\text {blank }}$ was determined as the standard deviation obtained for 5 injections of a standard at $\left.5 \mu \mathrm{g} \mathrm{L}^{-1}\right)$ and a limit of quantification (LOQ) of $4 \mu \mathrm{g} \mathrm{L}^{-1}$ (10s blank criteria). Intraday precision $\left(n=10\right.$, standard at $\left.10 \mu \mathrm{g} \mathrm{L}^{-1}\right)$ was $2.0 \%$ 


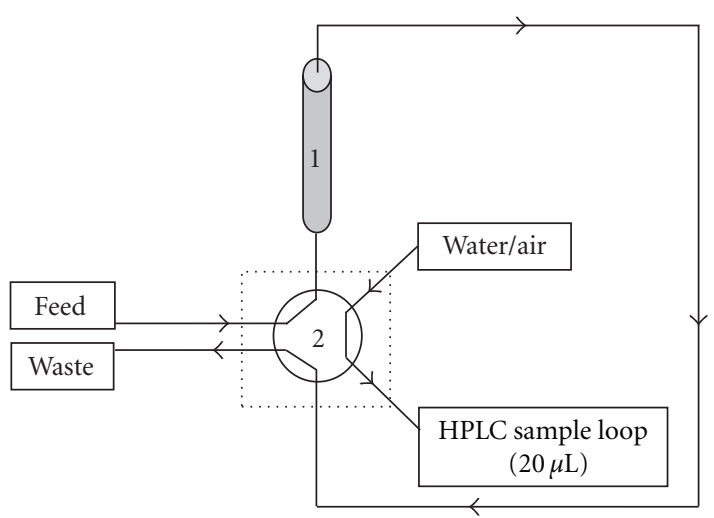

(a)

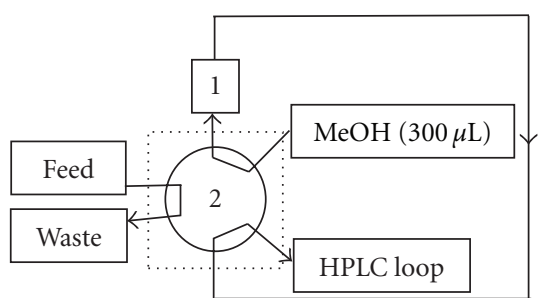

(b)

Figure 2: Diagram of the "online" mini-SPE column HPLC-UV system developed. 1: mini-SPE column; 2: six-port rotary valve (Model 5020 Low Pressure Valve, Rheodyne). (a) Valve position during feed (concentration) step; (b) valve position during desorption and HPLC analysis.

whilst inter-day precision ( $n=10$ consecutive days, standard at $10 \mu \mathrm{g} \mathrm{L}^{-1}$ ) was $5.6 \%$.

The limits obtained for the HPLC methods are excessive for the appropriate determination of the trace amounts of caffeine likely to be expected in environmental and waste waters (few parts per trillion) and so sample preparation is needed. Moreover, sample treatment is always required when measuring compounds at trace levels in a complex matrix as wastewaters. The analysis of different samples obtained at the influent of a WWTP, after filtration through $0.45 \mu \mathrm{m}$ filters to eliminate particulate matter, showed that the matrix effects (e.g., presence of large amounts of organic matter in these samples) resulted in large peaks at the beginning of the chromatograms with long tailing that made it impossible to analyze caffeine at levels below $20 \mu \mathrm{g} \mathrm{L}^{-1}$.

3.2. SPE Clean-Up and Preconcentration. SPE is a standard methodology for the extraction of caffeine for water samples $[2,9,17,18]$. Here, two different approaches were evaluated and compared for the clean-up and preconcentration of caffeine from water samples: (i) commercial single use SPE cartridges with a C18 stationary phase and (ii) a mini-SPE column filled with the same sorbent.

3.2.1. Commercial SPE Cartridges ("Off-Line" Method). The breakthrough volume of commercial Accubond ODS sorbents was determined to evaluate the efficiency of this sorbent. A breakthrough volume of $26 \mathrm{mg}$ of caffeine $(52 \mathrm{~mL}$ for a $500 \mathrm{mg} \mathrm{L}^{-1}$ solution) was found for the AccuBond cartridges. Bibliographic and preliminary analysis in the laboratory showed that levels of caffeine found in water samples had a maximum expected concentration of ca. $100 \mu \mathrm{g} \mathrm{L}^{-1}$ [6], which results in a breakthrough volume of ca. $260 \mathrm{~L}$ at this level. As a result, no saturation of the Accubond sorbent is expected in the analysis of up to $1 \mathrm{~L}$ samples.

Different elution solvents and mixtures were evaluated. Acetonitrile was not appropriate because it did not yield quantitative recoveries of caffeine from the sorbent. Methanol or methanol-water mixtures yielded quantitative
TABLE 1: Caffeine recoveries obtained with methanol-water mixtures as the elution solvent $(n=3$, values in brackets correspond to the standard deviation). Sorbent conditioning: $2 \mathrm{~mL}$ methanol and $2 \mathrm{~mL}$ Milli-Q water; feed solution: $100 \mathrm{~mL}$ standard at $0.1 \mathrm{mg} \mathrm{L}^{-1}$;

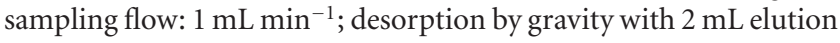
mixture.

\begin{tabular}{lc}
\hline$\%$ methanol & Recovery $(\%)$ \\
\hline 100 & $96.5(0.7)$ \\
80 & $98(2)$ \\
70 & $101(1)$ \\
60 & $92(1)$ \\
40 & $19.0(0.7)$ \\
20 & $0(-)$ \\
0 & $0(-)$ \\
\hline
\end{tabular}

recoveries when a minimum of $60 \%$ methanol was present in the elution solution (Table 1). Evaluation of the elution volume showed that $2 \mathrm{~mL}$ were enough for the quantitative elution of caffeine in all the conditions tested. A recovery percentage $\geq 96 \%$ was obtained at all elution flows tested $\left(1,2,5 \mathrm{~mL} \mathrm{~min}^{-1}\right.$ and gravity elution). An elution mixture of $2 \mathrm{~mL}$ methanol-water $(60: 40)$ by gravity was selected for further analyses.

The low expected concentration of the samples requires large volumes to be concentrated through the SPE sorbent, thus the use of high sampling flows will decrease the time of analysis. The evaluation of sampling different flow rates showed that there were no significant differences between the recoveries obtained in the range from 1 to $25 \mathrm{~mL} \mathrm{~min}^{-1}(P=$ 0.21 , ANOVA test, 3 replicates at each flow). A sampling flow of $25 \mathrm{~mL} \mathrm{~min}^{-1}$, resulting in a loading time of 40 minutes, was chosen for the analysis of $1 \mathrm{~L}$ samples.

The experimental LOD obtained in the analysis of fortified WWTP samples $(1000 \mathrm{~mL})$ with the "off-line" SPE HPLC-UV procedure was $0.1 \mu \mathrm{gL}^{-1}$. This value was sufficiently low as to ensure appropriate determination of caffeine in wastewater samples. However, it was still excessive 
for the analysis of surface waters since levels in the order of few $n g L^{-1}$ have been reported $[2,16,19]$. Intraday precision $(n=10)$ was $6 \%$.

3.2.2. Mini-SPE Column ("On-Line" Method). To reduce LODs, different "on-line" SPE/HPLC-UV methodologies for caffeine determination have been proposed with detection limits of 0.1 [18] and 0.05 [17] $\mu \mathrm{g} \mathrm{L}^{-1}$ ), using sample volumes of $100 \mathrm{~mL}$. We evaluated different mini-column designs for "on-line" SPE-HPLC-UV in order to obtain improved efficiency, sensitivity and speed in the determination of caffeine in surface waters.

Recovery was evaluated with minicolumns containing 10,50 , and $100 \mathrm{mg}$ of sorbent. For these assays, the whole elution solution was collected and mixed, and then a $20 \mu \mathrm{L}$ aliquot was injected into the HPLC system to determine the amount of caffeine recovered. Nonquantitative recovery (39 $\pm 11 \%, n=3$ ) was obtained for the first amount of sorbent. Quantitative recoveries were obtained for both 50 $(95 \pm 5 \%, n=3)$ and $100 \mathrm{mg}(101 \pm 2 \%, n=3)$ of sorbent, with no statistical significant differences between both values ( $t$-test, $P=0.18$ ). A weight of $100 \mathrm{mg}$ was chosen for subsequent analyses to prevent saturation of the column by matrix components when surface waters were analyzed.

The study of the volume of methanol needed for the quantitative elution with the mini-SPE column showed that volumes below $150 \mu \mathrm{L}$ did not yield quantitative recoveries. A volume of $300 \mu \mathrm{L}$ was chosen for further analyses.

For "on-line" analysis, the elution volume was sent directly to the HPLC injection valve. Once the first portion of solution appeared at the end of the loop, the valve was turned to the injection position to send the first $20 \mu \mathrm{L}$ portion of the elution solution to the chromatographic column.

Reproducibility of the mini-SPE column method was evaluated at different concentration levels $(15,25,50$, and $\left.100 \mathrm{ng} \mathrm{L}^{-1}\right)$ with the conditions selected. Intraday precision ( $n=10)$ was $<12 \%$. Statistical analysis confirmed that quantitative recoveries $(\geq 95 \%)$ were obtained at all levels. The evaluation of samples at $10 \mathrm{ng} \mathrm{L}^{-1}$ yielded significant smaller recoveries.

LOD of the "on-line" system was determined for a minimum recovery of $50 \%$, and it was experimentally found to be $5 \mathrm{ng} \mathrm{L}^{-1}$. LOQ was fixed at $15 \mathrm{ng} \mathrm{L}^{-1}$. The linearity of the "online" method was confirmed in the range between 15 and $200 \mathrm{ng} \mathrm{L}^{-1}$. Note that the LOD obtained with the "on-line" mini-column is one order of magnitude below LOD obtained using MS detection [12, 16].

Figure 3 shows the chromatograms obtained for a standard at $50 \mathrm{ng} \mathrm{L}^{-1}$ analyzed with the conventional "off-line" SPE methodology (Figure 3(a)) and the "on-line" mini-SPE column (Figure $3(\mathrm{~b})$ ). Detection limit with the "off-line" SPE method (i.e., $100 \mathrm{ng} \mathrm{L}^{-1}$ ) was above the concentration of the sample and caffeine was not detected with this methodology. The "on-line" method allowed the quantitative determination of the same sample. Besides the reduction in the LOD method, the mini-column methodology allows to work with reduced sample $(100 \mathrm{~mL})$ and elution volumes $(300 \mu \mathrm{L})$, which leads to improved efficiency and speed of analysis.

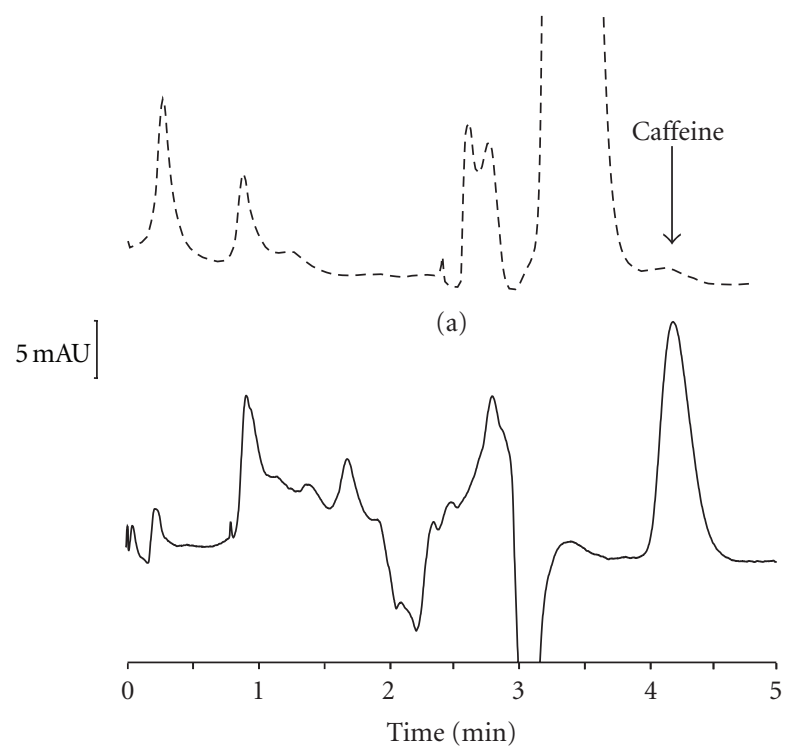

(b)

FIGURE 3: Chromatograms obtained for the analysis of a standard at $50 \mathrm{ng} \mathrm{L}^{-1}$. (a) Analysis with the "off-line" SPE method, and (b) analysis of the same standard with the "on-line" mini-SPE/HPLCUV method.

One of the problems in the analysis of water samples using an "on-line" system is the presence of considerable amounts of organic matter in some samples that can lead to a fast saturation of the mini-SPE columns. It is therefore important to evaluate the number of samples that can be analyzed with a continuous "on-line" system before saturation takes place. To this end, we evaluated two groups of samples: (i) surface waters and (ii) WWTP samples. When relatively "clean" samples were analyzed, as in the case of tap, surface waters and tertiary effluents from WWTPs, levels of organic matter were small and different samples were analyzed with the same mini-SPE column with no significant recovery losses. We were able to analyze ten consecutive fortified surface water samples with the same mini-SPE column with no variations in efficiency (recoveries $\geq 96 \%$ ). WWTP samples, however, present a large amount of organic matter, which cannot be completely removed from the sorbent with the elution solvent. This reduces the efficiency of the sorbent after each analysis. For this type of sample, the "on-line" mini-column was not appropriate for analyzing consecutive samples and it had to be changed after each analysis.

\subsection{Water Analysis}

3.3.1. Surface Waters. Figure 4 shows the chromatogram obtained in the analysis of a surface water sample with the developed "on-line" method. Caffeine was not detected in the sample (Figure 4(a)). The analysis of the sample fortified at $15 \mathrm{ng} \mathrm{L}^{-1}$ gave a $101 \%$ recovery (Figure $4(\mathrm{~b})$ ). The analysis of all surface waters analyzed during the study showed equivalent results (caffeine levels below detection 
TABLe 2: Caffeine levels detected $\left(\mu \mathrm{g} \mathrm{L}^{-1}\right)$ at the three WWTPs evaluated. Sampling dates: (1) 6th of July, (2) 11th of July, (3) 14th of July, (4) 18 th of July, (5) 21st of July, (6) 27th of July, and (7) 4th of October.

\begin{tabular}{|c|c|c|c|c|c|c|c|}
\hline \multirow{2}{*}{ WWTP } & \multicolumn{7}{|c|}{ Sampling date } \\
\hline & 1 & 2 & 3 & 4 & 5 & 6 & 7 \\
\hline \multicolumn{8}{|l|}{ Empuriabrava } \\
\hline Influent & 104.7 & 110.7 & 77.0 & 82.3 & 119.7 & 70.5 & 85.2 \\
\hline Biological effluent & 0.6 & 1.2 & nd & nd & 0.5 & 0.8 & nd \\
\hline Lagoon & nq & $\mathrm{nq}$ & nd & nd & nd & nd & nd \\
\hline Wetlands influent & nd & nd & nd & nd & nd & nd & nd \\
\hline 1st wetland & nd & nd & nd & nd & nd & nd & nd \\
\hline 2nd wetland & nd & nd & nd & nd & nd & nd & nd \\
\hline 3rd wetland & nd & nd & nd & nd & nd & nd & nd \\
\hline \multicolumn{8}{|l|}{ Pals } \\
\hline Influent & 55.3 & 60.3 & 59.0 & 77.6 & 57.9 & 49.4 & 54.7 \\
\hline Biological effluent & nd & nd & nd & nq & nd & nd & nd \\
\hline Secondary clarifier & nd & nd & nd & nd & nd & nd & nd \\
\hline \multicolumn{8}{|l|}{ Palamós } \\
\hline Influent & 80.7 & 89.1 & 75.5 & 92.4 & 49.4 & 82.6 & 66.6 \\
\hline Primary effluent & 58.8 & 67.8 & 44.1 & 64.4 & 44.4 & 55.3 & 53.1 \\
\hline Biological effluent & nq & nd & 1.2 & nd & 0.5 & nd & nd \\
\hline Tertiary & nd & nd & nd & nd & nd & nd & nd \\
\hline
\end{tabular}

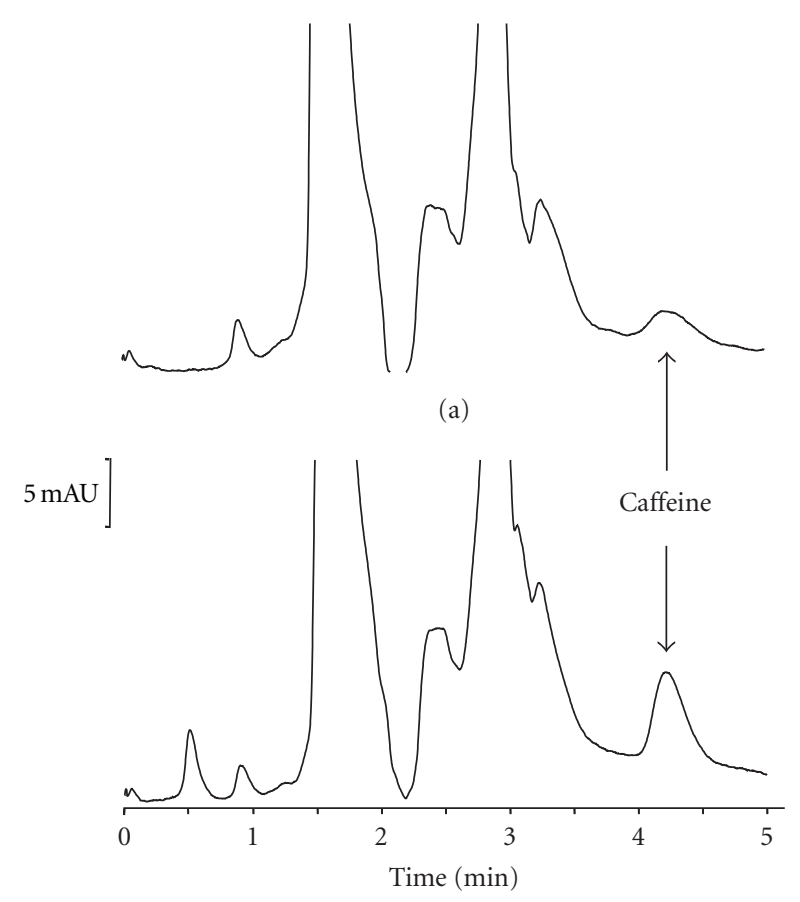

(b)

FIGURE 4: Chromatograms obtained for the analysis of a surface natural water with the "on-line" mini-SPE/HPLC-UV method. (a) Direct analysis of the sample and (b) analysis of the same sample fortified at $15 \mathrm{ng} \mathrm{L}^{-1}$. limit, $5 \mathrm{ng} \mathrm{L}^{-1}$ ), except for one isolated sample downstream from the Palamós plant where a value of $60 \mathrm{ng} \mathrm{L}^{-1}$ was found.

3.3.2. WWTP Samples. As indicated previously, the "on-line" method did not give appropriate clean-up for continuous monitoring of samples within WWTPs. For this reason, the "off-line" method was used as it allows a most effective cleanup of these samples. Table 2 shows the results obtained in the analysis of samples from three WWTPs at different sampling points in each plant.

The aim of this study was to obtain information about the removal of caffeine in the different steps involved in the water treatment of urban wastewaters. Caffeine was quantified in all the influent samples from the three WWTPs at levels in the range $50-120 \mu \mathrm{g} \mathrm{L}^{-1}$, with mean values of $92.9 \mu \mathrm{g} \mathrm{L}^{-1}$ in Empuriabrava, $59.2 \mu \mathrm{g} \mathrm{L}^{-1}$ in Pals and $76.6 \mu \mathrm{g} \mathrm{L}^{-1}$ in Palamós. Calculated amounts of caffeine by person and day were of the same order for each influent plant when concentration values were normalized taking into account the population and the amount of water treated in each WWTP: 23.2, 14.8, and $15.2 \mathrm{mg}$ person $^{-1}$ day $^{-1}$, respectively. These results are similar to those obtained in other studies $[2,9,20]$.

The effect of a primary treatment to remove solid particles from the water entering the WWTP was evaluated in the Palamós plant. Levels at the effluent of the primary treatment were determined as this treatment was designed 
in this plant exclusively to remove solid particles. Previous studies $[9,10]$ indicated that sorption/sedimentation of caffeine is negligible and attributed this to its low sorption potential $\left(\log K_{\mathrm{ow}} \sim 0\right)$. Thus, this treatment is expected to have a small effect on the removal of such a hydrophilic compound. As can be seen in Table 2, the caffeine reduction was between 10 and $42 \%($ mean $=28 \%$, sd $=11)$ after this treatment.

The results obtained indicate that the biological treatment had the highest effect on the removal of caffeine with more than $99 \%$ of the total caffeine being eliminated after this treatment in all the WWTPs evaluated. These results agree with previous studies $[2,10]$, where it was found that biodegradation was the dominant elimination process of caffeine and other xenobiotics contaminants in waters and determined residence half-life times between 0.8 and 5.0 hours in WWTPs due to the high microbial activity in activated sludge. Globally, the WWTPs evaluated showed good efficiency in caffeine removal as this compound was not detected in any sample at the effluent of the plants.

\section{Conclusions}

The developed methodologies based on solid phase extraction followed by HPLC with UV detection have been successfully applied to the determination of caffeine in environmental waters and throughout the wastewater treatment process. Significant removal of caffeine in the four WWTPs examined was demonstrated and the biological stage of the wastewater treatment process was confirmed as being responsible for this removal. The results also indicate the suitability of caffeine as a marker for untreated domestic wastewater.

\section{Acknowledgment}

This study has been financed by the MICINN (Spanish Ministry of Education and Science), Project CTM2008-06847C02-02/TECNO.

\section{References}

[1] Z. Chen, P. Pavelic, P. Dillon, and R. Naidu, "Determination of caffeine as a tracer of sewage effluent in natural waters by online solid-phase extraction and liquid chromatography with diode-array detection," Water Research, vol. 36, no. 19, pp. 4830-4838, 2002.

[2] I. J. Buerge, T. Poiger, M. D. Müller, and H. R. Buser, "Combined sewer overflows to surface waters detected by the anthropogenic marker caffeine," Environmental Science and Technology, vol. 40, no. 13, pp. 4096-4102, 2006.

[3] R. L. Seiler, S. D. Zaugg, J. M. Thomas, and D. L. Howcroft, "Caffeine and pharmaceuticals as indicators of waste water contamination in wells," Ground Water, vol. 37, no. 3, pp. 405410, 1999.

[4] D. J. Birkett and J. O. Miners, "Caffeine renal clearance and urine caffeine concentrations during steady state dosing. Implications for monitoring caffeine intake during sports events," British Journal of Clinical Pharmacology, vol. 31, no. 4, pp. 405408, 1991.
[5] M. Bonati, R. Latini, and F. Galletti, "Caffeine disposition after oral doses," Clinical Pharmacology and Therapeutics, vol. 32, no. 1, pp. 98-106, 1982.

[6] S. D. Kim, J. Cho, I. S. Kim, B. J. Vanderford, and S. A. Snyder, "Occurrence and removal of pharmaceuticals and endocrine disruptors in South Korean surface, drinking, and waste waters," Water Research, vol. 41, no. 5, pp. 1013-1021, 2007.

[7] A. Y. C. Lin, T. H. Yu, and S. K. Lateef, "Removal of pharmaceuticals in secondary wastewater treatment processes in Taiwan," Journal of Hazardous Materials, vol. 167, no. 1-3, pp. 1163-1169, 2009.

[8] L. J. Fono and D. L. Sedlak, "Use of the chiral pharmaceutical propranolol to identify sewage discharges into surface waters," Environmental Science and Technology, vol. 39, no. 23, pp. 9244-9252, 2005.

[9] I. J. Buerge, T. Poiger, M. D. Müller, and H. R. Buser, "Caffeine, an anthropogenic marker for wastewater contamination of surface waters," Environmental Science and Technology, vol. 37, no. 4, pp. 691-700, 2003.

[10] S. Leschik, A. Musolff, M. Martienssen et al., "Investigation of sewer exfiltration using integral pumping tests and wastewater indicators," Journal of Contaminant Hydrology, vol. 110, no. 34, pp. 118-129, 2009.

[11] M. B. Henjum, R. M. Hozalski, C. R. Wennen, W. Arnold, and P. J. Novak, "Correlations between in situ sensor measurements and trace organic pollutants in urban streams," Journal of Environmental Monitoring, vol. 12, no. 1, pp. 225-233, 2010.

[12] S. S. Verenitch, C. J. Lowe, and A. Mazumder, "Determination of acidic drugs and caffeine in municipal wastewaters and receiving waters by gas chromatography-ion trap tandem mass spectrometry," Journal of Chromatography A, vol. 1116, no. 12, pp. 193-203, 2006.

[13] T. A. Bellar and W. L. Budde, "Determination of nonvolatile organic compounds in aqueous environmental samples using liquid chromatography/mass spectrometry," Analytical Chemistry, vol. 60, no. 19, pp. 2076-2083, 1988.

[14] T. Ternes, M. Bonerz, and T. Schmidt, "Determination of neutral pharmaceuticals in wastewater and rivers by liquid chromatography-electrospray tandem mass spectrometry," Journal of Chromatography A, vol. 938, no. 1-2, pp. 175-185, 2001.

[15] P. R. Gardinali and X. Zhao, "Trace determination of caffeine in surface water samples by liquid chromatographyatmospheric pressure chemical ionization-mass spectrometry (LC-APCI-MS)," Environment International, vol. 28, no. 6, pp. 521-528, 2002.

[16] A. L. Batt, I. B. Bruce, and D. S. Aga, "Evaluating the vulnerability of surface waters to antibiotic contamination from varying wastewater treatment plant discharges," Environmental Pollution, vol. 142, no. 2, pp. 295-302, 2006.

[17] J. Patsias and E. Papadopoulou-Mourkidou, "Development of an automated on-line solid-phase extraction-highperformance liquid chromatographic method for the analysis of aniline, phenol, caffeine and various selected substituted aniline and phenol compounds in aqueous matrices," Journal of Chromatography A, vol. 904, no. 2, pp. 171-188, 2000.

[18] Z. Chen, P. Pavelic, P. Dillon, and R. Naidu, "Determination of caffeine as a tracer of sewage effluent in natural waters by online solid-phase extraction and liquid chromatography with diode-array detection," Water Research, vol. 36, no. 19, pp. 4830-4838, 2002. 
[19] J. Wu, S. Yue, R. Hu, Z. Yang, and L. Zhang, "Use of caffeine and human pharmaceutical compounds to identify sewage contamination," International Journal of Civil and Environmental Engineering, vol. 2, no. 2, pp. 98-102, 2010.

[20] L. J. Standley, L. A. Kaplan, and D. Smith, "Molecular tracers of organic matter sources to surface water resources," Environmental Science and Technology, vol. 34, no. 15, pp. 3124-3130, 2000. 


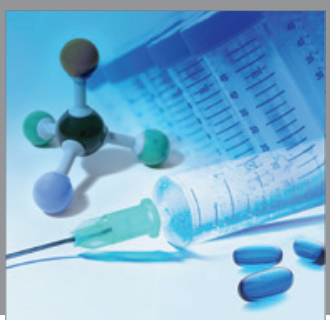

International Journal of

Medicinal Chemistry

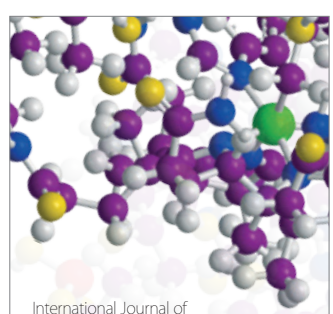

Carbohydrate Chemistry

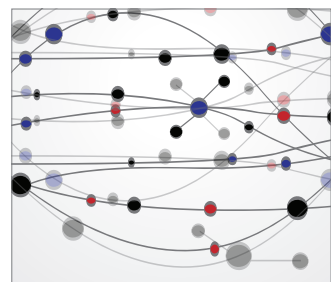

The Scientific World Journal
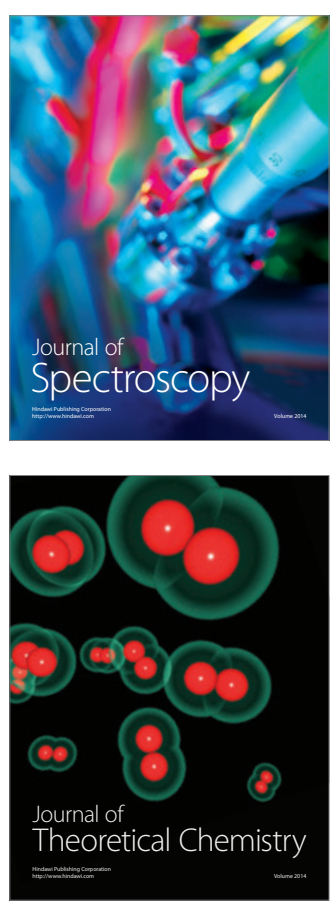
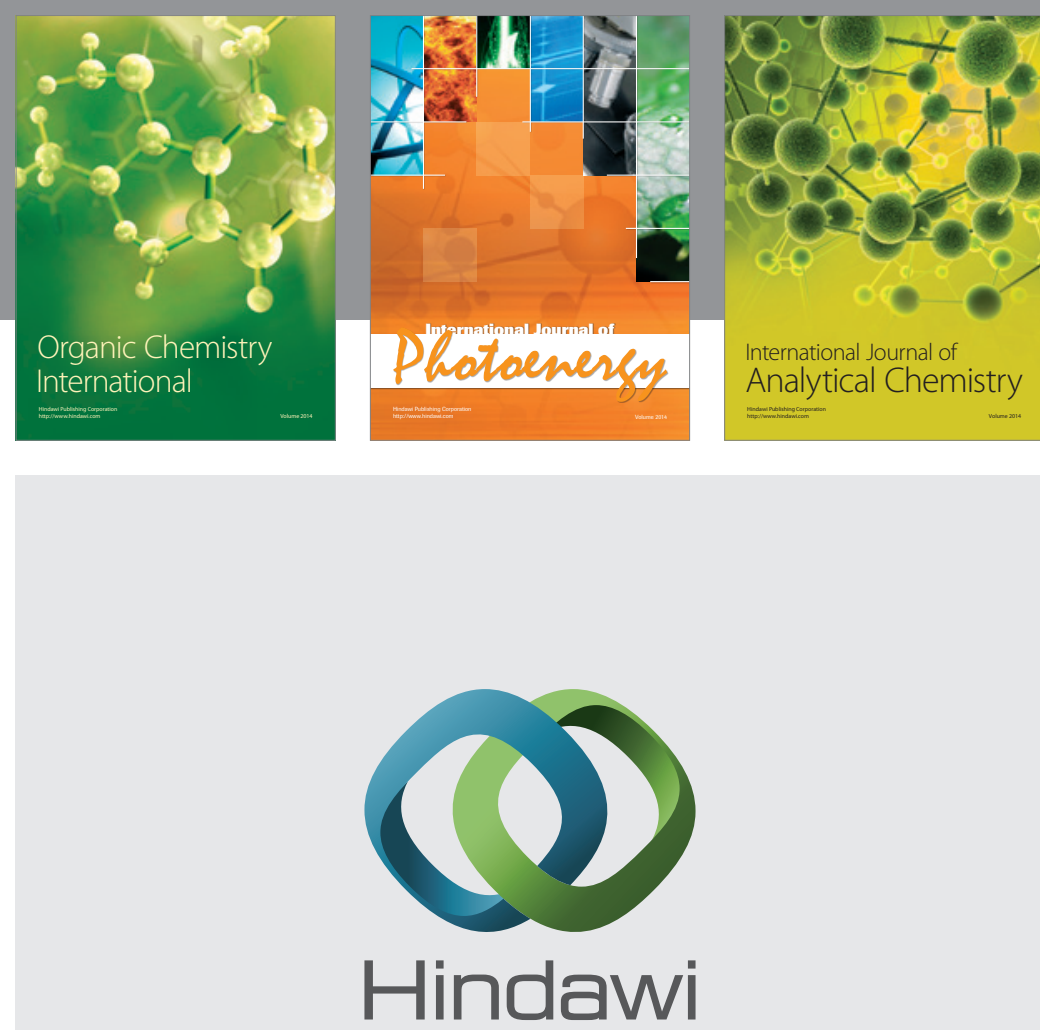

Submit your manuscripts at

http://www.hindawi.com
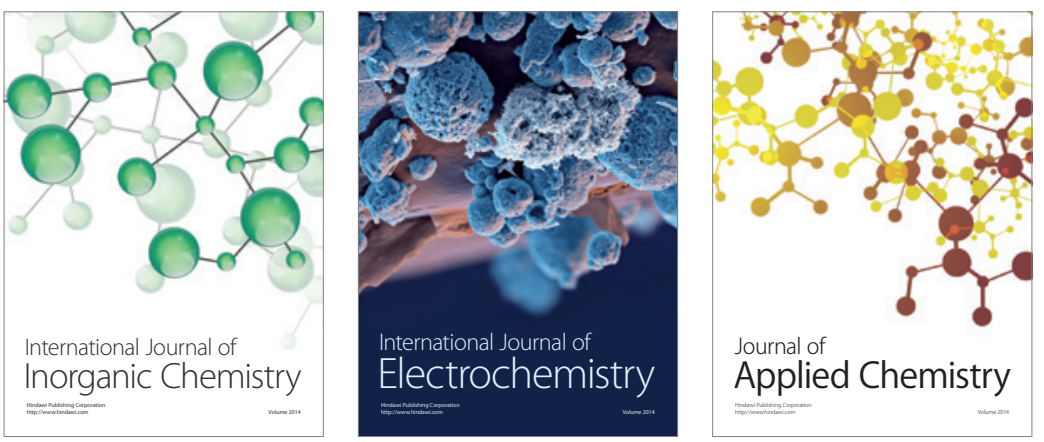

Journal of

Applied Chemistry
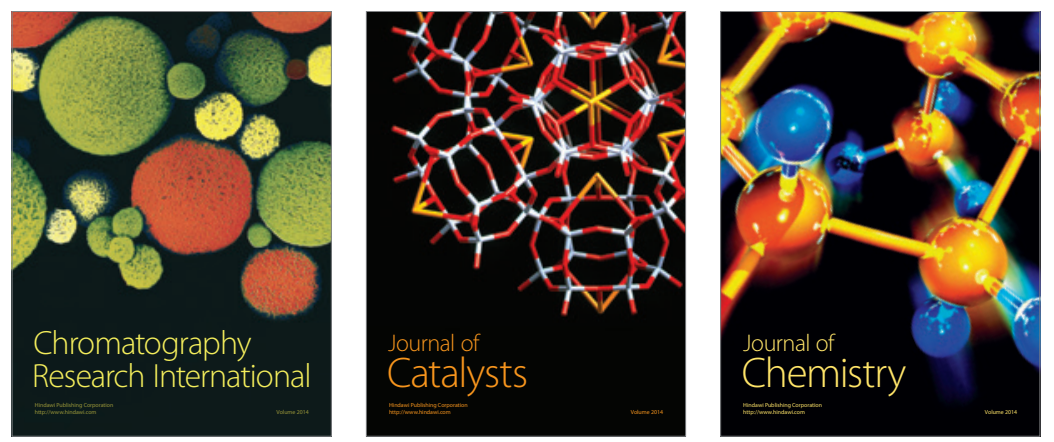
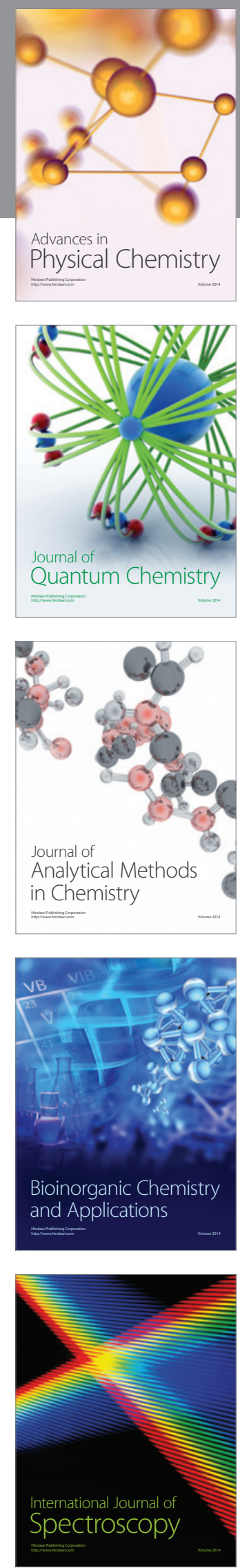